\title{
Effect of acute pentylenetetrazol injection induced epileptic seizures on rat dentate gyrus at different postnatal ages
}

\author{
Heba K. Mohamed ${ }^{1}$, Sohair A. Eltony ${ }^{2}$ \\ Departments of ${ }^{1}$ Anatomy and ${ }^{2}$ Histology and Cell Biology, Faculty of Medicine, Assiut University, Assiut, Egypt
}

\begin{abstract}
Epilepsy is one of the most common neurological disorders, its prevalence approximately from $0.5 \%$ to $2 \%$ of the general population. Generalized seizures could lead to several morphological changes in the brain. This study aimed to investigate the morphological effects of a single convulsive dose of pentylenetetrazol (PTZ) on rat dentate gyrus at different postnatal ages. Thirty-six male Wistar rats were used at the following postnatal ages: P10, P21, and P90 (12 rats per each age). The animals in each age were equally divided into two groups: group I, control and group II, treated with a single intraperitoneal injection of PTZ (55 mg/kg). After confirmation of generalized tonic-clonic seizures, specimens from the right dentate gyrus were processed for light and electron microscopy. In PTZ-treated groups, the number of granule cells significantly decreased. Dark granule cells appeared in the deep layers of the granule cells in P10 and with the progress of age, they significantly increased in number and extended into the superficial layers of the granule cells. The dendritic spines diminished. Glial fibrillary acidic protein and caspase-3 expression increased. Ultrastructurally, granule cells showed irregular shaped nucleus, dilated rough endoplasmic reticulum (RER) cisternae, mitochondria with damaged cristae, large vacuoles, lysosomes, and lipofuscin granules. Dark granule cells characterized by electron-dense nucleus and cytoplasm containing disorganized Golgi bodies, swollen mitochondria with damaged cristae, numerous free ribosomes and few long strands of RER. Astrocytes had hypertrophied cell body. Acute treatment with PTZ-induced epileptic seizures caused toxic effect on the structure of rat dentate gyrus at different postnatal ages.
\end{abstract}

Key words: Dentate gyrus, Pentylenetetrazol, Epileptic seizures

Received April 10, 2019; Revised June 30, 2019; Accepted September 20, 2019

\section{Introduction}

Epilepsy is one of the most common neurological disorders affecting people of all ages, race and social class, its prevalence approximately from $0.5 \%$ to $2 \%$ of the general population

\footnotetext{
Corresponding author:

Sohair A. Eltony (iD)

Department of Histology and Cell Biology, Faculty of Medicine, Assiut University, Assiut 71111, Egypt

Tel: +20-01001031153, Fax:+20-0882080278, E-mail: sohair_eltony@ yahoo.com
}

with much higher incidence in developing countries [1]. It has resulted from an abnormal electrical discharge of a group of neurons in the brain and exhibits as seizure [2]. The hippocampal dentate gyrus (DG) has been suspected to play a role in seizure initiation. It has been reported that seizures correlate with loss of hippocampal DG GABAergic neurons [3, 4]. Generalized seizures could lead to several morphological changes in the brain owing to hypoxia and acidosis [5].

The DG is the main target for cortical inputs to the hippocampal formation [6]. It plays an important role in supporting hippocampal-dependent learning and memory [7]. Moreover, it is one of the brain regions that continually generate new neurons in adulthood [8]. While most of the cortical neuro- 
genesis in rats occurs during the second and third week of prenatal period, hippocampus formation is completed during the first 2 weeks of postnatal life [9].

Pentylenetetrazol (PTZ) has a central nervous system stimulant epileptogenic property. It is a gamma-aminobutyric acid receptor antagonist commonly used as a convulsing drug in experimental studies [10]. A clonic-tonic seizure episode was induced by a single convulsive dose of PTZ resulted in a gradual decline in short-term memory function and cognitive impairment [11].

This study aimed to investigate the morphological effects of a single convulsive dose of PTZ on rat DG at different postnatal ages.

\section{Materials and Methods}

A total number of 36 male Wistar rats were used in this study at the following postnatal ages: P10, P21, and P90. Twelve rats from each age were used. The animals were purchased from the Central Animal House, Faculty of Medicine, Assiut University. All animal procedures were in accordance with the standards set forth in the guidelines for the care and use of experimental animals by the Committee for the Purpose of Supervision of Experiments on Animals (CPCSEA) and according to the National Institute of Health (NIH) protocol and approved by the Institutional Ethics Committee of Assiut University. The animals were housed in clean capacious cages under normal day and night cycles and appropriate temperature $\left(25^{\circ} \mathrm{C} \pm 5^{\circ} \mathrm{C}\right)$, fed rat chow (standard rat pellets) and water ad libitum.

\section{Animal groups}

The animals in each age were equally divided into two groups: rats in group I (normal vehicle control), intraperitoneally injected with $0.5 \mathrm{ml} 0.9 \% \mathrm{NaCl}$; rats in group II (seizure group), given a single intraperitoneal injection of PTZ (Sigma, St. Louis, MO, USA) at a dose of $55 \mathrm{mg} / \mathrm{kg}$ dissolved in $0.5 \mathrm{ml}$ $0.9 \% \mathrm{NaCl}[12]$. During the next 30 minutes, all rats were observed for seizures activity according to Cole et al's study [13]. After confirmation of generalized tonic-clonic seizures, animals were anesthetized with ether, their hearts were exposed, and then perfusion was done.

For light microscope, two rats from each animal group were perfused intracardially with $10 \%$ formaldehyde solution. The skull was opened, and the brain was removed carefully. The right cerebral hemisphere was cut and immersed in the fixative. Then the specimens were processed for preparation of paraffin blocks. Coronal serial sections $(5 \mu \mathrm{m})$ were cut using a microtome (Leica RM 2125RT, Nussloch, Germany), and every 10th section was stained with hematoxylin and eosin [14]. For demonstration of neuronal processes, the right cerebral hemispheres of two rats from each animal group were fixed in a freshly prepared Golgi-Cox mixture for six weeks in dark. Processing and staining techniques were carried out according to Drury and Wallington's study [14].

For electron microscope, two rats from each group were perfused intracardially with $4 \%$ glutaraldehyde in cacodylate buffer ( $\mathrm{pH}$ 7.4). Specimens from the right DG were cut into thin slices $(1 \times 1 \mathrm{~mm})$ and immersed in $4 \%$ glutaraldehyde in cacodylate buffer ( $\mathrm{pH} 7.4$ ) for 24 hours and postfixed in $1 \%$ osmium tetroxide in phosphate buffer for 2 hours [15]. Semithin sections $(0.5-1 \mu \mathrm{m})$ were cut with glass knives on the ultramicrotome (LKB Bromma 8800 UltratomeR III, Stockholm, Sweden) and stained with $1 \%$ toluidine blue $(\mathrm{pH} 7.3)$ for examination on a light microscope (Bx50, Model Bx50F-3, SC09160, Olympus, Tokyo, Japan). Ultrathin sections (50-80 $\mathrm{nm}$ ) were cut from selected areas of the blocks on a Reichert ultramicrotome (WILDM3Z, Leica, Wien, Austria) and contrasted with uranyl acetate and lead citrate. These sections were examined using the transmission electron microscope (Jeol E.M.-100 CX11, Tokyo, Japan) and photographed at 80 $\mathrm{kV}$.

\section{Immunohistochemical study}

Expression of glial fibrillary acidic protein (GFAP) and caspase-3 (apoptotic marker) was detected in the right DG in formalin-fixed paraffin-embedded sections. Sections $(5 \mu \mathrm{m})$ were deparaffinized in xylene and rehydrated in alcohol. The GFAP Rabbit Polyclonal Antibody (Thermo Fisher Scientific, Fremont, CA, USA) was used at 1:100 dilution for 20 minutes at room temperature. The caspase 3 (CPP32) Ab-4, rabbit polyclonal antibody (Thermo Fisher Scientific) was used at 1:100 dilution for 30 minutes at room temperature. Sections were processed according to the manufacturer instructions using the universal kit (Ultra Vision LP system, HRP polymer and DAB plus chromogen, Thermo Fisher Scientific). After completion of the reaction, counterstaining was done using Mayer's hematoxylin, dehydrated and cover-slipped using DPX (Oxford Laboratory Reagents, Mumbai, India).

\section{Morphometric study}

Using computer-assisted image analysis (Soft Imaging 
System, AnalySIS-2004, Olympus); the number of cell layers and the number of dark granule cells in granule layer (GL) of DG was counted/ $\mathrm{mm}^{2}$ in semithin sections using a $\times 100$ objective lens. The number of spines was counted/granule cell dendrite in Golgi-Cox stained sections using a $\times 100$ objective lens. The number of caspase- 3 positive cells was counted per $\mathrm{mm}^{2}$ in GL of DG in immunoassayed sections using a $\times 100$ objective lens. The GFAP positive stained area was measured per $\mathrm{mm}^{2}$ in GL of DG in immunoassayed sections using a $\times 400$ objective lens. Measurements were done in five nonoverlapping fields in 10 serial sections from different animals for each group.

\section{Statistical analysis}

The morphometric data of each animal group were statistically analyzed using the computer statistics Prism-5.0 package (GraphPad Software, Inc., San Diego, CA, USA). Oneway analysis of variance (ANOVA) followed by NewmanKelus test as a post-test was employed to compare the studied animal group. The results were expressed as mean \pm standard deviation (SD). $P$-value $<0.05$ was considered significant.
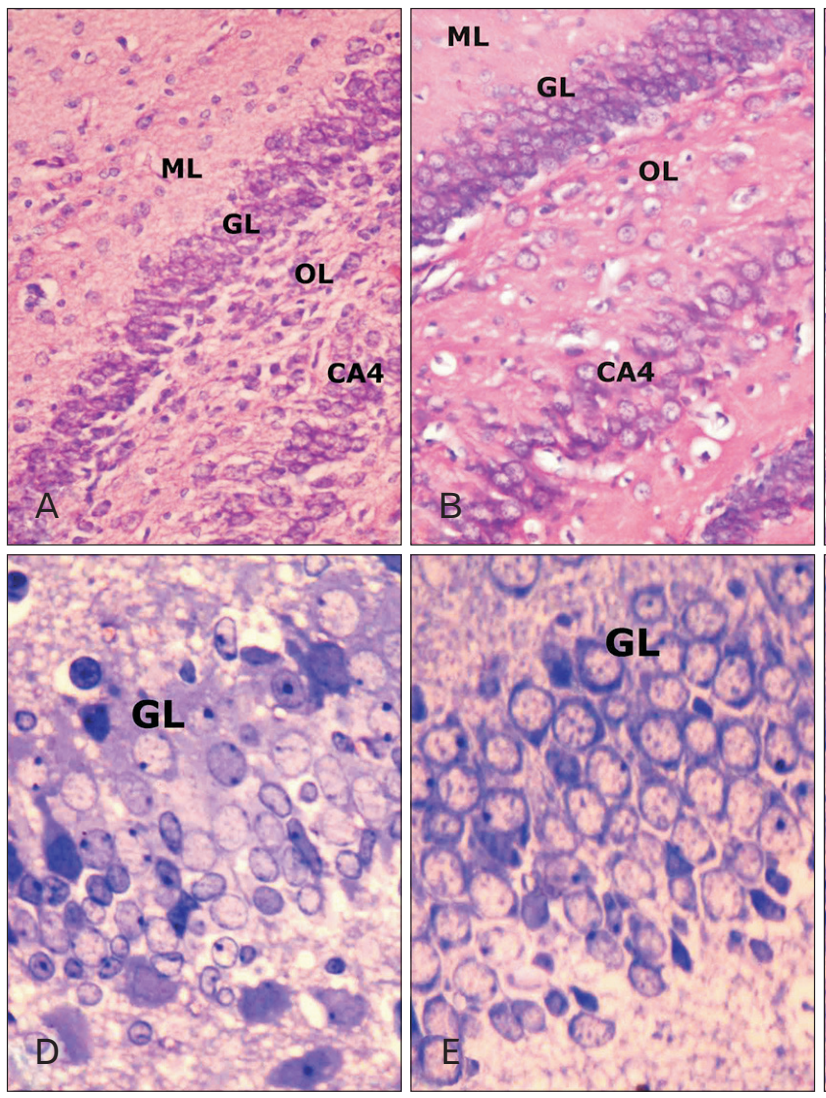

\section{Results}

\section{Histological results}

In control groups, the DG was a C-shaped capping the free border of CA4 of the hippocampus proper. It consisted of three layers; an outer molecular layer (ML), a middle GL and an inner polymorphic layer (OL) or the hilus (Fig. 1A-C). The OL was highly cellular, while, the ML was less cellular. GL was the principal cell layer, formed of many layers of granule cells with oval nuclei and scanty basophilic cytoplasm (Fig. 1A-C). The number of granule cell layers was significantly increased

Table 1. Number of cell layers per $\mathrm{mm}^{2}$ in GL of DG in the control (c) and treated $(\mathrm{t})$ groups

\begin{tabular}{cccc}
\hline Group & Mean \pm SD & Range & $P$-value \\
\hline $\mathrm{P} 10 \mathrm{c}^{\mathrm{a})}$ & $5.60 \pm 0.51$ & $5.0-6.0$ & 0.001 \\
$\mathrm{P} 10 \mathrm{t}^{\mathrm{b})}$ & $4.20 \pm 0.41$ & $4.0-5.0$ & \\
$\mathrm{P} 21 \mathrm{c}$ & $6.20 \pm 0.86$ & $5.0-7.0$ & \\
$\mathrm{P} 21 \mathrm{t}$ & $5.13 \pm 0.35$ & $5.0-6.0$ & \\
$\mathrm{P} 90 \mathrm{c}^{\mathrm{a})}$ & $5.40 \pm 0.51$ & $5.0-6.0$ & \\
$\mathrm{P} 90 \mathrm{t}^{\mathrm{b})}$ & $3.93 \pm 0.46$ & $3.0-5.0$ & \\
\hline
\end{tabular}

GL, granule layer; DG, dentate gyrus. ${ }^{\text {a) }} \mathrm{P} 10 \mathrm{c}$ vs. $\mathrm{P} 90 \mathrm{c}(P>0.05) .{ }^{\mathrm{b})} \mathrm{P} 10 \mathrm{t}$ vs. P90t $(P>0.05)$.

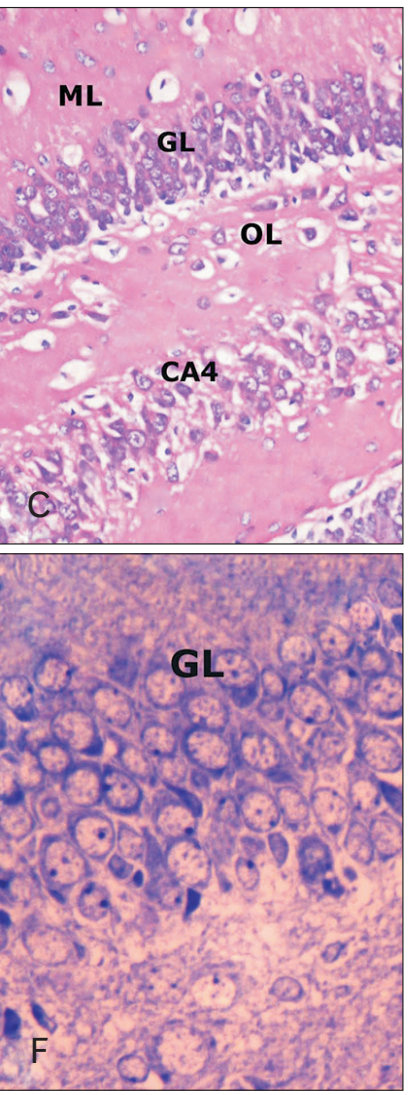

Fig. 1. Group I: P10 (A, D), P21 (B $\mathrm{E})$, and $\mathrm{P} 90(\mathrm{C}, \mathrm{F})$. Paraffin sections stained with hematoxylin and eosin $(\times 400)(\mathrm{A}-\mathrm{C})$; showing the three layers of the dentate gyrus from outside to inside; molecular layer (ML), granule cell layer (GL), and polymorphic layer (OL). Part from the CA4 of the hippocampus proper. (D-F) Semithin sections stained with toluidine blue $(\times 1,000)$; showing the GL. 
from P10 to P21 (Fig. 1D, E). It was 5.60 \pm 0.50 (mean \pm SD; range, 5.0-6.0) in P10 and 6.20 \pm 0.86 (range, 5.0-7.0) in P21 (Table 1, Fig. 2). While P90 revealed significant decrease in the number of granule cell layers compared to the previous age groups (Fig. 1F). It ranged from 5.0 to 6.0 (mean \pm SD, $5.40 \pm 0.50$ ) (Table 1, Fig. 2).

In the treated groups (P10, 20, and 90), the number of

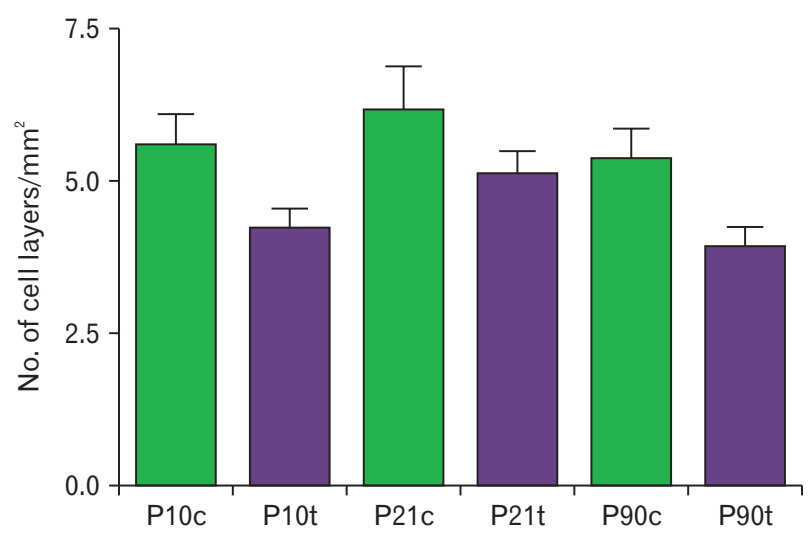

Fig. 2. The mean number $( \pm S D)$ of cell layers $/ \mathrm{mm}^{2}$ in granule cell layer of dentate gyrus in the control (c) and treated $(\mathrm{t})$ groups. granule cell layers significantly decreased $(P<0.001)$ compared to the corresponding control age groups. It was $4.20 \pm 0.41$ (mean \pm SD; range, 4.0-5.0) in P10, 5.13 \pm 0.35 (range, 5.0-6.0) in P21 and 3.93 \pm 0.46 (range, 3.0-5.0) in P90 (Table 1, Fig. 2). Dark granule cells appeared in the deep layers of the granule cells in P10 (Fig. 3A, D) and with the progress of age; they significantly $(P<0.001)$ increased in number (Fig. 3B, E) and extended into the superficial layers of the granule cells (Fig. $3 \mathrm{C}, \mathrm{F}$ ). Their number was $1.7 \pm 0.75$ (range, 1.0-3.0) in P10, $7.0 \pm 1.1$ (range, 5.0-8.0) in P21, and 12.0 \pm 4.9 (range, 7.0-18.0) in P90 (Table 2, Fig. 4).

\section{Golgi-Cox method results}

In P10 control group, the dentate granule cells revealed

Table 2. Number of dark granule cells per $\mathrm{mm}^{2}$ in GL of DG in the treated (t) groups

\begin{tabular}{cccc}
\hline Group & Mean \pm SD & Range & $P$-value \\
\hline P10t & $1.7 \pm 0.75$ & $1.0-3.0$ & 0.001 \\
P21t & $7.0 \pm 1.1$ & $5.0-8.0$ & \\
P90t & $12.0 \pm 4.9$ & $7.0-18.0$ & \\
\hline
\end{tabular}

GL, granule layer; DG, dentate gyrus.
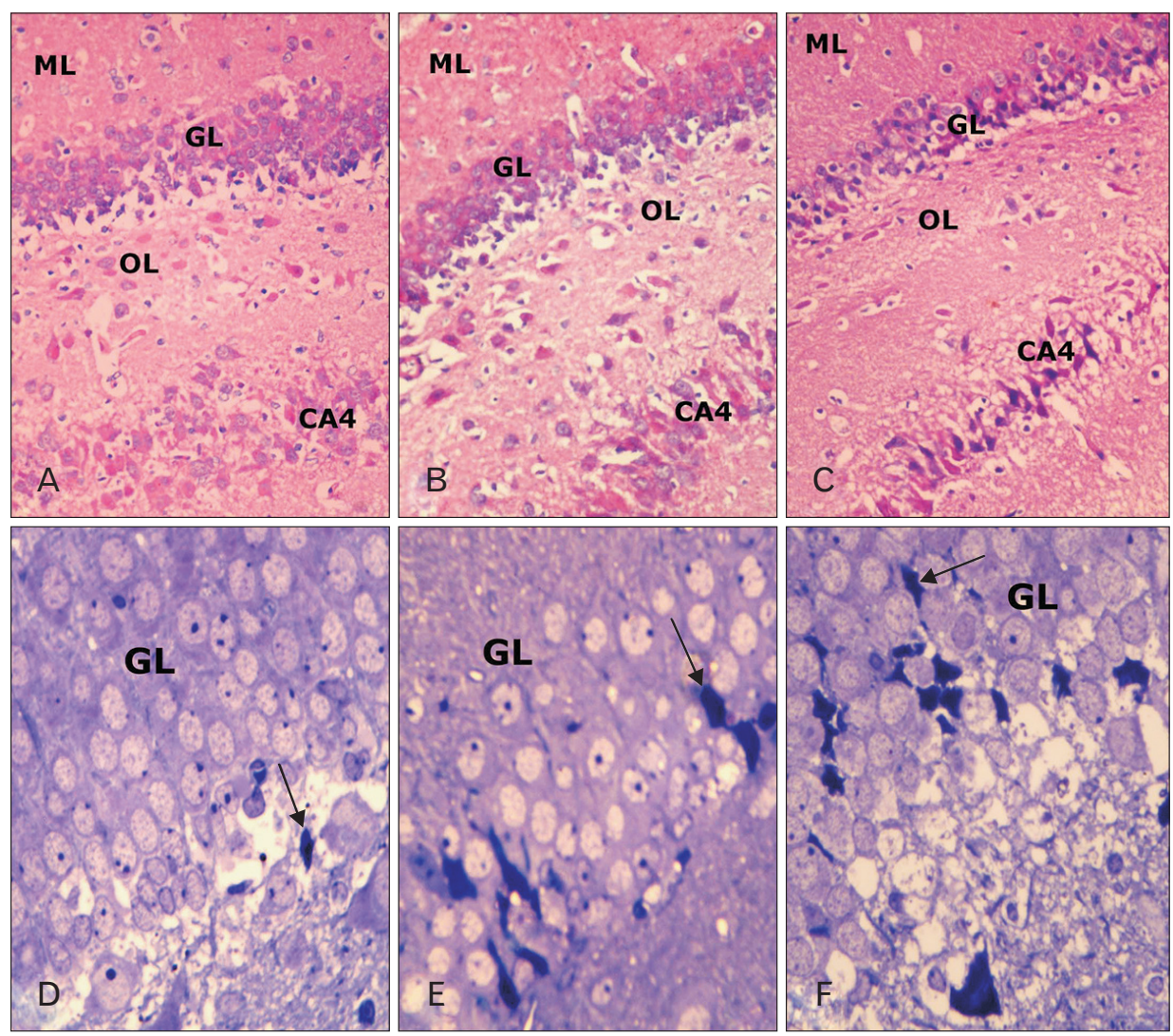

Fig. 3. Group II: P10 (A, D), P21 (B, E), and P90 (C, F). Paraffin sections stained with (hematoxylin and eosin, $\times 400(\mathrm{~A}-\mathrm{C})$; showing the three layers of the dentate gyrus from outside to inside; molecular layer (ML), granule cell layer (GL), polymorphic layer (OL). Part from the CA4 of the hippocampus proper. (D-F) Semithin sections stained with toluidine blue $(\times 1,000)$; showing the GL. Arrows indicate dark granule cells. 
oval cell bodies with one to three primary stem dendrites arising from the superior pole of the somata, giving rise to dendritic tree oriented toward the ML. Their surfaces revealed spines (Fig. 5A). A single thin axon arose from their inferior poles towards the hilus (Fig. 5A). With the progress of age, the granule cells revealed longer widely spreading dendritic tree with more side branches and several spines (Fig. 5B, C). The number of dendritic spines was $5.1 \pm 1.0($ mean $\pm \mathrm{SD}$; range, 3.0-6.0) in P10, 6.9 \pm 1.1 (range, 6.0-9.0) in P21, and 12.0 \pm 2.8 (range, 8.0-16.0) in P90 (Table 3, Fig. 6).

The DG of the treated groups revealed diminished dendritic spines (Fig. 7A-C). The number of dendritic spines was $3.1 \pm 1.0$ (mean $\pm \mathrm{SD}$; range, 2.0-5.0) in P10, 4.5 \pm 1.1 (range, 3.0-6.0) in P21, and 6.4 \pm 3.2 (range, 4.0-14.0) in P90 (Table 3, Fig. 6).

\section{Immunohistochemical results}

The DG of the control groups revealed GFAP positively stained astrocytes. In P10 astrocytes had longitudinally oriented processes (Fig. 8A). The GFAP-positive area was

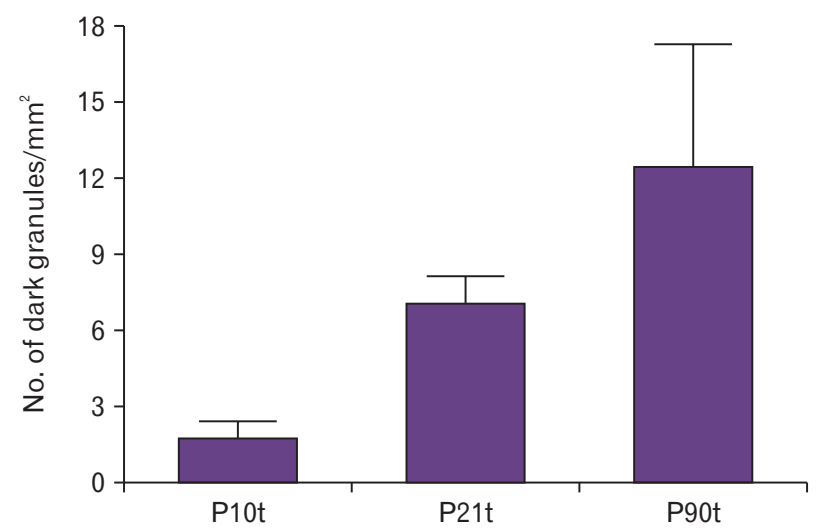

Fig. 4. The mean number $( \pm S D)$ of dark granule cells $/ \mathrm{mm}^{2}$ in granule cell layer of dentate gyrus in the treated groups.
$11,556 \pm 1,488 \mu \mathrm{m}^{2}$ (mean \pm SD; range, 9,267-14,546 $\mu \mathrm{m}^{2}$ ) (Table 4, Fig. 9). GFAP reaction increased in P21 DG and astrocytes appeared more populated and stellate in shape (Fig. 8B). The GFAP positive area was $132,905 \pm 21,318 \mu \mathrm{m}^{2}$ (range, 91,415-163,615 $\mu \mathrm{m}^{2}$ ) (Table 4, Fig. 9). P90 DG revealed strongly GFAP stained astrocytes with numerous extending processes (Fig. 8C). The GFAP positive area was $176,469 \pm 24,822 \mu \mathrm{m}^{2}$ (range, 112,493-226,698 $\mu \mathrm{m}^{2}$ ) (Table 4, Fig. 9).

Table 3. Number of spines/granule cell dendrite in the control (c) and treated (t) groups

\begin{tabular}{lccc}
\hline Group & Mean \pm SD & Range & $P$-value \\
\hline $\mathrm{P} 10 \mathrm{c}^{\mathrm{a})}$ & $5.1 \pm 1.0$ & $3.0-6.0$ & 0.001 \\
$\mathrm{P} 10 \mathrm{t}^{\mathrm{a})}$ & $3.1 \pm 1.0$ & $2.0-5.0$ & \\
$\mathrm{P} 21 \mathrm{c}^{\mathrm{b})}$ & $6.9 \pm 1.1$ & $6.0-9.0$ & \\
$\mathrm{P} 21 \mathrm{t}^{\mathrm{b})}$ & $4.5 \pm 1.1$ & $3.0-6.0$ & \\
$\mathrm{P} 90 \mathrm{c}$ & $12.0 \pm 2.8$ & $8.0-16.0$ & \\
$\mathrm{P} 90 \mathrm{t}$ & $6.4 \pm 3.2$ & $4.0-14.0$ & \\
\hline
\end{tabular}

${ }^{\text {a) }}$ P10c vs. P10t $(P<0.05)$, P21t vs. P10c $(P>0.05) .{ }^{\text {b) }}$ P21c vs. P21t $(P<0.01)$, P90t vs. P21c $(P>0.05)$.

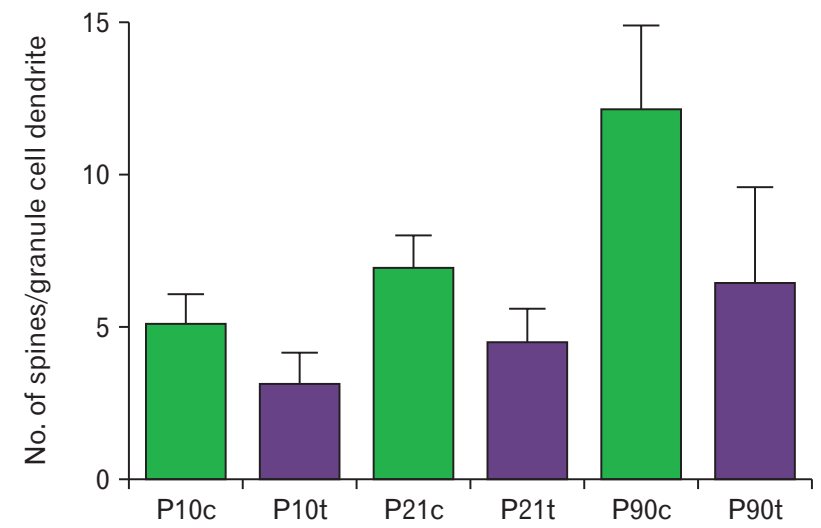

Fig. 6. The mean number $( \pm S D)$ of spines/granule cell dendrite in the control $(c)$ and treated $(t)$ groups.
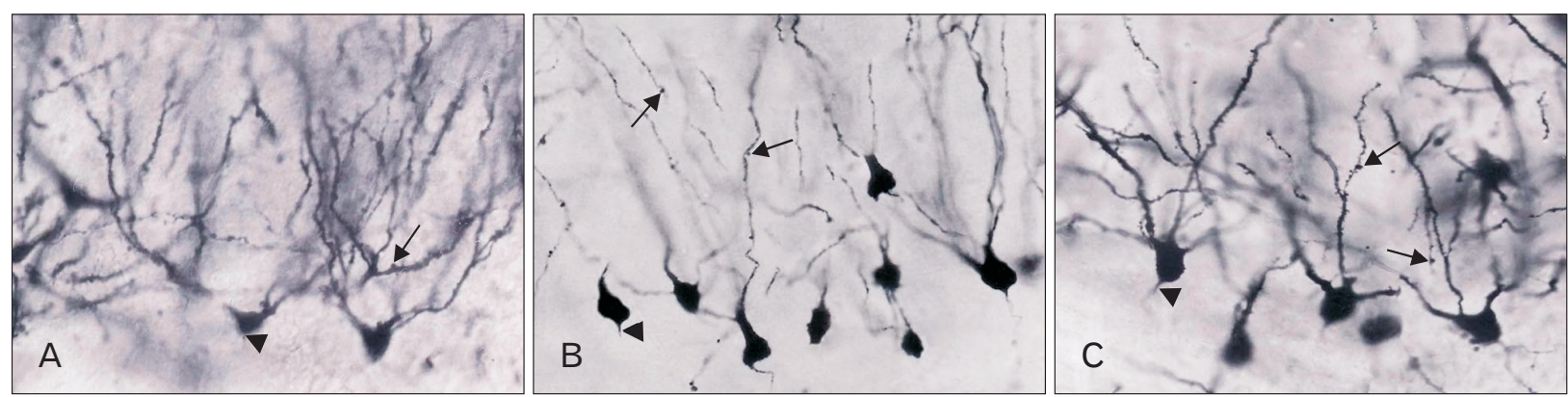

Fig. 5. Group I: P10 (A), P21 (B), and P90 (C). Golgi-Cox stained sections (×1,000); showing spines (arrows) on the dendritic branches. Arrowhead points to the axon. 

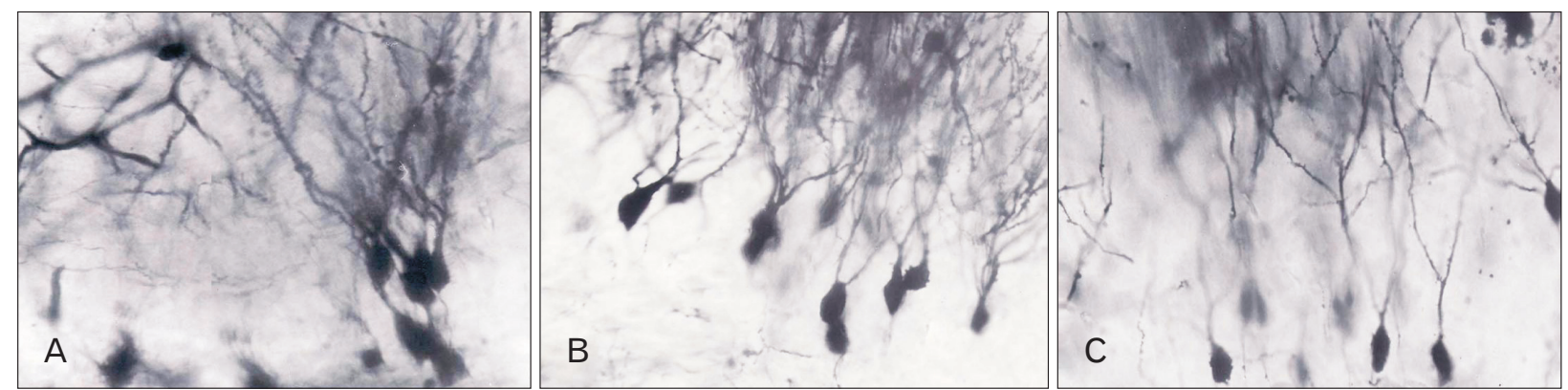

Fig. 7. Group II: P10 (A), P21 (B), and P90 (C). Golgi-Cox stained sections (×1,000); showing diminished or loss of dendritic spines compared to the corresponding control age groups.
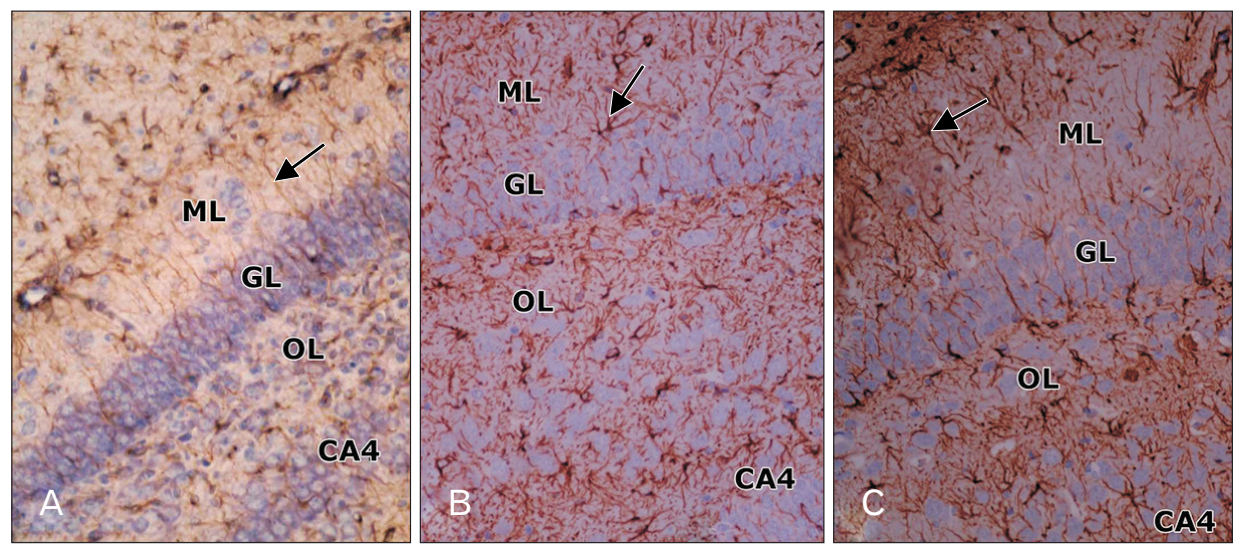

Fig. 8. Group I: P10 (A), P21 (B), and P90 (C). Glial fibrillary acidic protein immunostained paraffin sections $(\times 400)$, molecular layer (ML), granule cell layer (GL), polymorphic layer (OL). Part from the CA4 of the hippocampus proper. Note, the longitudinally oriented astrocytic processes (arrow) in P10, the stellate- shaped astrocytes (arrow) in P21 and astrocytes with numerous extending processes (arrow) in P90.

Table 4. GFAP area $\left(\mu \mathrm{m}^{2}\right)$ in GL of DG in the control (c) and treated (t) groups

\begin{tabular}{cccc}
\hline Group & Mean \pm SD & Range & $P$-value \\
\hline P10c & $11,556 \pm 1,488$ & $9,267-14,546$ & 0.001 \\
P10t & $173,867 \pm 17,187$ & $139,830-202,750$ & \\
P21c & $132,905 \pm 21,318$ & $91,415-163,615$ & \\
P21t & $239,781 \pm 39,076$ & $167,755-303,930$ & \\
P90c & $176,469 \pm 24,822$ & $112,493-226,698$ & \\
P90t & $350,092 \pm 50,177$ & $250,729-391,700$ & \\
\hline
\end{tabular}

GFAP, glial fibrillary acidic protein; GL, granule layer; DG, dentate gyrus.

In the treated groups, GFAP reaction increased compared to the corresponding control age groups (Fig. 10AC). The GFAP positive area was $173,867 \pm 17,187 \mu \mathrm{m}^{2}$ (range, $139,830-202,750 \mu \mathrm{m}^{2}$ ) in P10, 239,781 $\pm 39,076$ (range, $167,755-303,930$ ) in $\mathrm{P} 21$, and $350,092 \pm 50177$ (range, 250,729-391,700) in P90 (Table 4, Fig. 9).

Caspase- 3 expression was negative in the DG of the control groups (Fig. 11A-C). While in treated groups, the reaction was positive in some cells in the OL and deep layers of the granule cells. The reaction was predominantly cytoplasmic with some nuclear staining. In P10 few positive granule cells were observed in the deep layers of the granule cells (Fig.

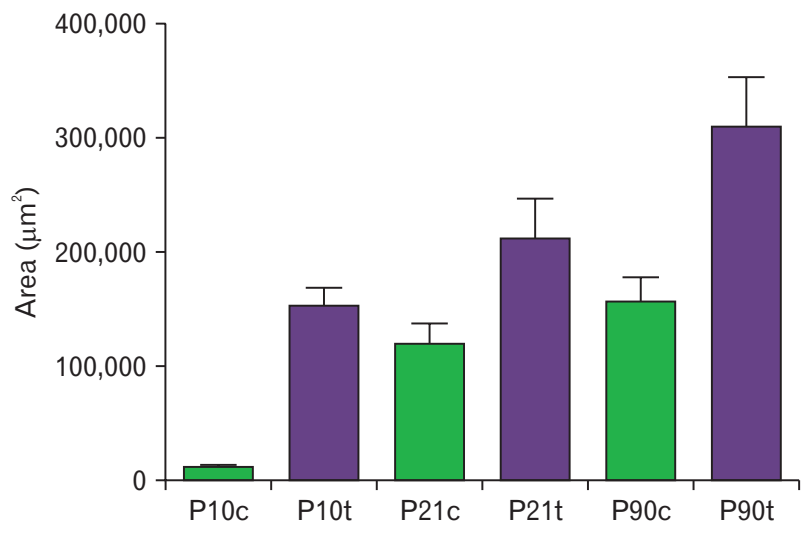

Fig. 9. Glial fibrillary acidic protein mean area $\left( \pm S D, \mu \mathrm{m}^{2}\right)$ in granule cell layer of dentate gyrus in the control $(c)$ and treated $(t)$ groups.

12A). They increased in number and extended into the superficial layers of the granule cells in P20 and P90 (Fig. 12B, C). The number of caspase-3-positive cells was $1.5 \pm 0.51$ (range, 1.0-2.0) in P10, 3.9 \pm 0.85 (range, 3.0-5.0) in P21, and 6.2 \pm 1.2 (range, 5.0-8.0) in P90 (Table 5, Fig. 13). 

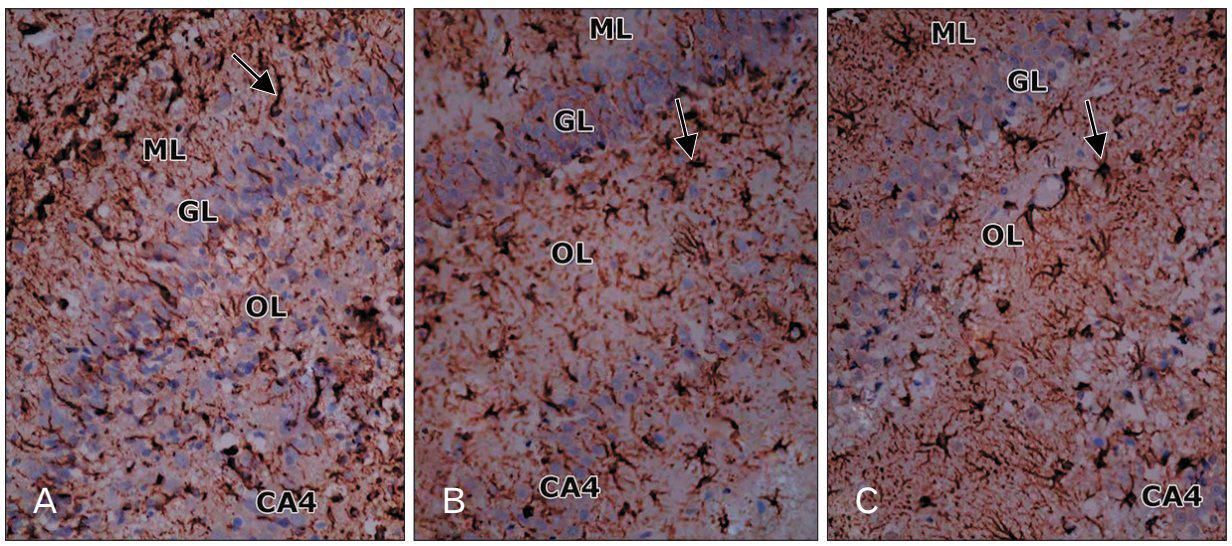

Fig. 10. Group II, P10 (A), P21 (B), and P90 (C). Glial fibrillary acidic protein (GFAP) immunostained paraffin sections $(\times 400)$, molecular layer $(\mathrm{ML})$, granule cell layer $(\mathrm{GL})$, polymorphic layer (OL). Part from the CA4 of the hippocampus proper. Note, the increased GFAP reaction (arrows) compared to the corresponding control age groups.
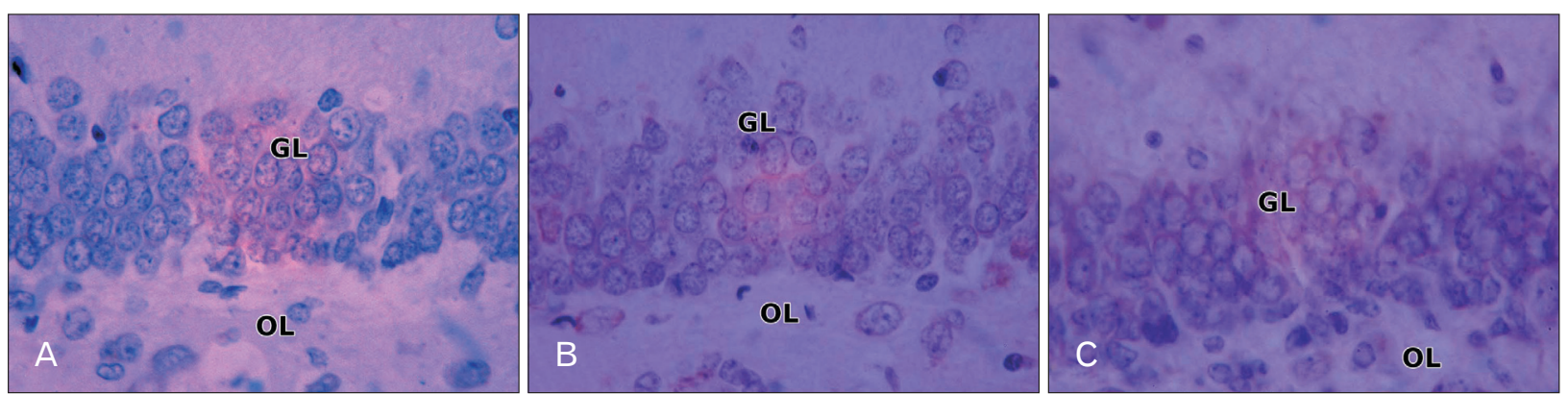

Fig. 11. Group I: P10 (A), P21 (B), and P90 (C). Caspase-3 immunostained paraffin sections $(\times 1,000)$, granule cell layer (GL), polymorphic layer $(\mathrm{OL})$; showing negative caspase-3 immunoreactivity.
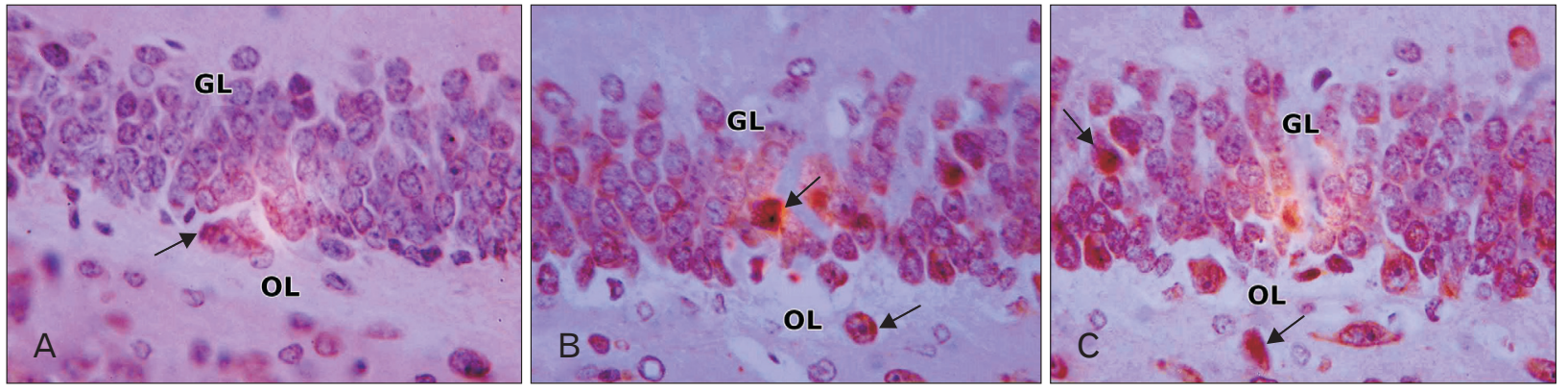

Fig. 12. Group II: P10 (A), P21 (B), and P90 (C). Caspase-3 immunostained paraffin sections $(\times 1,000)$, granule cell layer (GL), polymorphic layer $(\mathrm{OL})$; showing caspase-3 strong positive cells (arrows).

Table 5. Number of caspase-3 positive cells $/ \mathrm{mm}^{2}$ in GL of DG in the treated groups

\begin{tabular}{cccc}
\hline Group & Mean \pm SD & Range & $P$-value \\
\hline P10t & $1.5 \pm 0.51$ & $1.0-2.0$ & 0.001 \\
P21t & $3.9 \pm 0.85$ & $3.0-5.0$ & \\
P90t & $6.2 \pm 1.2$ & $5.0-8.0$ & \\
\hline
\end{tabular}

GL, granule layer; DG, dentate gyrus; $t$, treated.

\section{Electron microscopic results}

Ultrastructurally, granule cells of the DG in P10 control group revealed large oval euchromatic nuclei, containing few dense clumps of chromatin especially around the nuclear rim and their cytoplasm contained few mitochondria, rough endoplasmic reticulum (RER), and numerous free ribosomes (Fig. 14). Astrocytes in the granule cell layer had large round euchromatic nuclei with peripheral clumps of heterochromatin and their cytoplasm contained few mitochondria, RER and numerous free ribosomes (Fig. 14). With the progress of age, the cytoplasm of the granule cells and astrocytes underwent significant differentiation with an abundance of cytoplasmic organelles; mitochondria, RER and occasional 


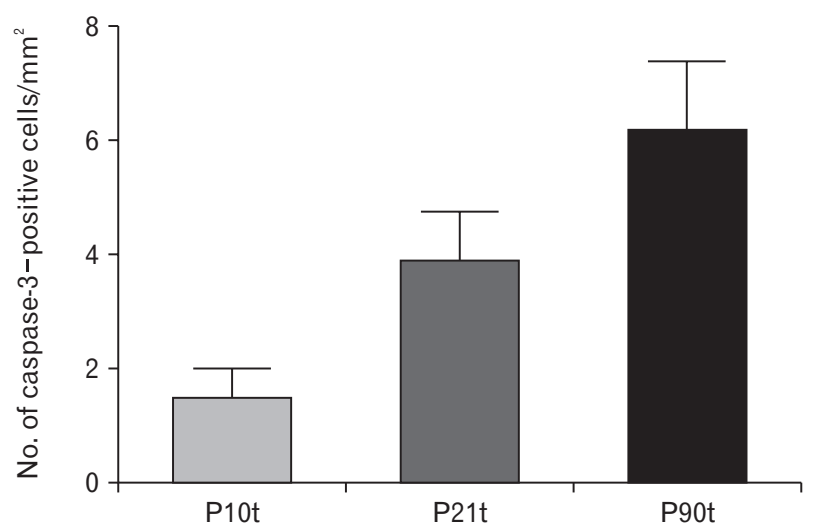

Fig. 13. The mean number of caspase-3-positive cells $/ \mathrm{mm}^{2}$ in granule cell layer of dentate gyrus in the treated $(\mathrm{t})$ groups.

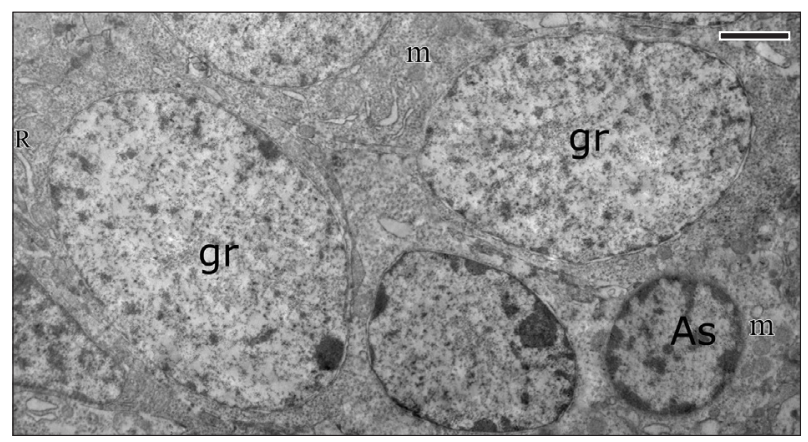

Fig. 14. Electron micrograph, granule cell layer, group I, P10. Granule cells (gr), mitochondria $(\mathrm{m})$, rough endoplasmic reticulum $(\mathrm{R})$, astrocyte (As) $(\times 7,200)$. Scale bar $=2 \mu \mathrm{m}$.

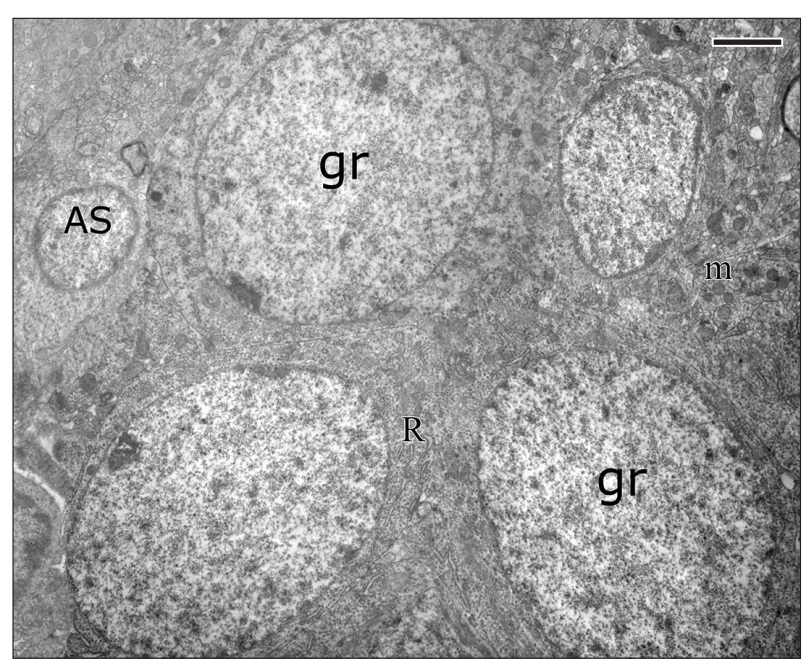

Fig. 15. Electron micrograph, granule cell layer, group I, P21. Granule cells $(\mathrm{gr})$, mitochondria $(\mathrm{m})$, rough endoplasmic reticulum $(\mathrm{R})$, astrocyte (As) $(\times 7,200)$. Scale bar $=2 \mu \mathrm{m}$. lysosomes (Figs. 15, 16).

Granule cells of the DG in P10-treated group contained dilated RER cisternae, some of which had electron-dense matrix populated by ribosomes, mitochondria with damaged cristae and lysosomes (Fig. 17). Astrocytes had large round euchromatic nuclei with peripheral clumps of heterochromatin and their cytoplasm contained few mitochondria with damaged cristae and dilated RER cisternae (Fig. 17). With the progress of age, granule cells revealed irregular shaped nucleus and their cytoplasm contained numerous free ribosomes, few RER, disorganized Golgi bodies, large vacuoles, lysosomes, and lipofuscin granules (Fig. 18). Dark granule cells appeared, characterized by electron-dense nucleus and cytoplasm containing disorganized Golgi bodies, swollen mitochondria

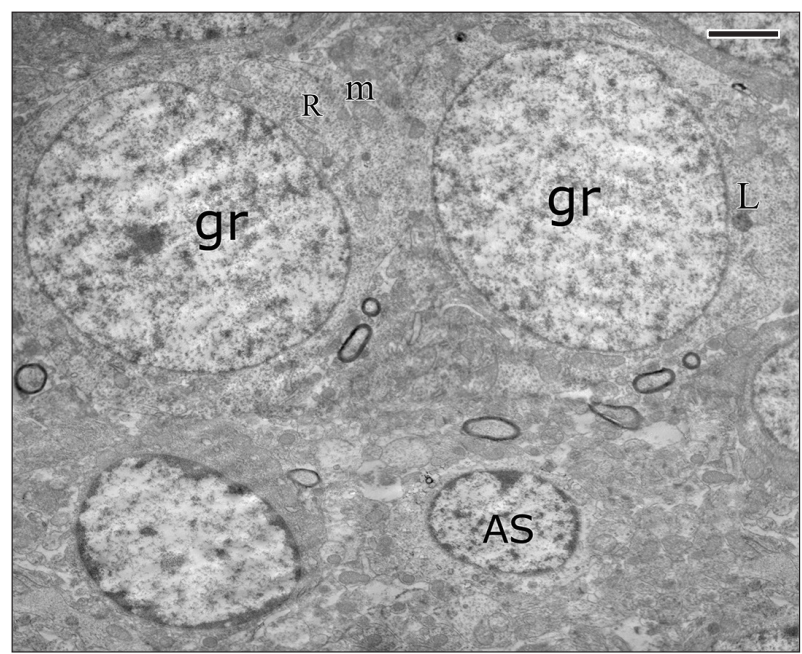

Fig. 16. Electron micrograph, granule cell layer, group I, P90. Granule cells (gr), mitochondria $(\mathrm{m})$, rough endoplasmic reticulum $(\mathrm{R})$, lysosome (L), astrocyte (As) $(\times 7,200)$. Scale bar $=2 \mu \mathrm{m}$.

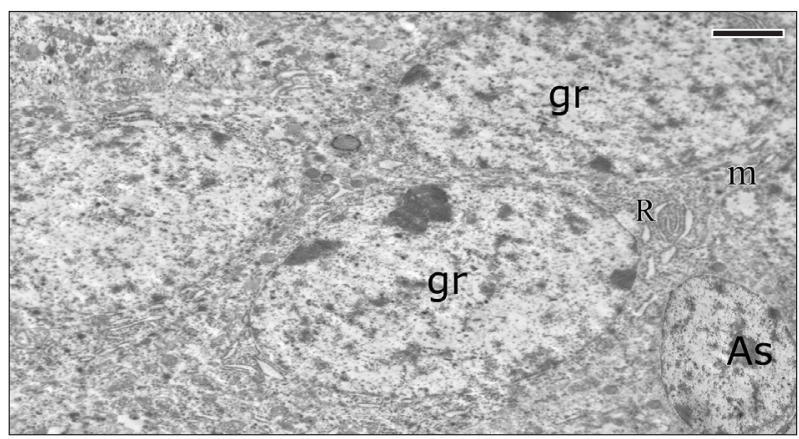

Fig. 17. Electron micrograph, granule cell layer, group II, P10. Granule cells ( gr), mitochondria with damaged cristae (m), dilated rough endoplasmic reticulum cisternae (R), lysosome (L), astrocyte (As) $(\times 7,200)$. Scale bar $=2 \mu \mathrm{m}$. 


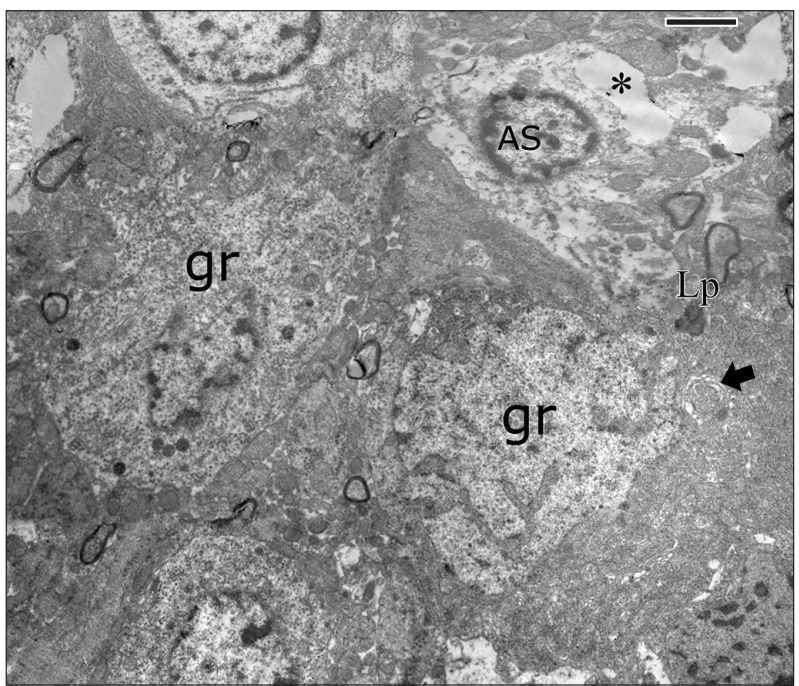

Fig. 18. Electron micrograph, granule cell layer, group II, P21. Granule cells (gr) with irregular nuclei, disorganized golgi (arrow), lipofuscin granules (Lp), astrocyte (As) with hypertrophied cell body, vacuole $\left(^{*}\right)$ $(\times 7,200)$. Scale bar $=2 \mu \mathrm{m}$.

with damaged cristae, numerous free ribosomes and few long strands of RER (Fig. 19). Astrocytes had hypertrophied cell body; containing euchromatic nucleus with few clumps of heterochromatin, free ribosomes, mitochondria and large vacuoles (Figs. 18, 19).

\section{Discussion}

The purpose of the present study was to investigate the morphologic effects of a single convulsive dose of PTZ on rat DG at different postnatal ages. It is generally accepted that rat pups of P10 roughly correspond to a term human infant, the P21 period is roughly equal to a 1-year-old human infant and P90 is equivalent to human adulthood $[16,17]$.

Based on our previous study, neurogenesis in the rat DG peaked during early postnatal stages leading to a considerable increase in cell number during this period. Then, it declined in adult animals [18]. This study revealed a significant decrease in the number of granule cell layers in PTZ-treated animals, concomitant with an increase in the number of dark granule cells. Dark granule cells appeared in the deep layers of the granule cells and with the progress of age, they extended into the superficial layers of the granule cells. It was reported that the deep subgranular zone contained granule cells that were derived postnatally from the hilar proliferative center that took over the production of new granule cells into adulthood [19]. Dark neurons were considered a manifestation of

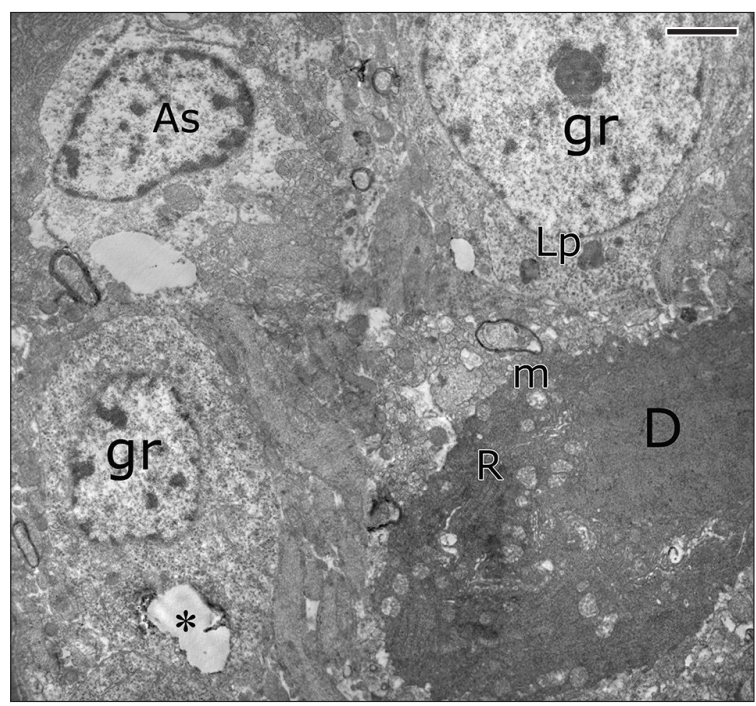

Fig. 19. Electron micrograph, granule cell layer, group II, P90. Granule cells (gr), lipofuscin granules (Lp), vacuole $\left({ }^{*}\right)$, dark granule cell (D), mitochondria with damaged cristae $(\mathrm{m})$, rough endoplasmic reticulum cisternae (R), astrocyte (As) with hypertrophied cell body $(\times 7,200)$. Scale bar $=2 \mu \mathrm{m}$.

neuronal injury and it has been proposed that brain tissues oxidative damages due to free radicals, glutamate, and aspartate have a role in the production of dark neurons [20]. Previous studies showed that PTZ-induced seizure caused dark neurons in the hippocampus [21-24]. It was indicated that single attack of seizures leads to apoptotic neuronal death [24]. Furthermore, caspase-3 expression was positive in this study in PTZ-treated animals. It has been evidenced that PTZinduced seizure causes expression of caspase- 3 gene as an active gene involved in programmed cell death. In agreement, Pavlova et al. [25] revealed that glutamate release, excessive excitability, and enhancement of intracellular calcium caused by PTZ-induced seizure, result in cell death. Furthermore, it was suggested that reactive oxygen species which are produced during seizure attacks, induce neuronal cell damages resulting in cell death, apoptosis, and necrosis [26]. Evidence from Kim and Jung [27] suggested that acidification of tissue which is a consequence of oxygen depletion might contribute to apoptosis.

Golgi-Cox method in PTZ-treated animals revealed reduction in granule cells dendritic spines. Consistently, Jiang et al. [28] observed dendritic spine loss in hippocampal neurons in a rat model of early-onset epilepsy. Dendritic spine loss thought to be a sign of dendritic differentiation [29], and the cognitive disorders reported in PTZ-induced seizures rat pups could be resultant from dendritic spine loss [30]. In addition, 
dendritic spine loss was linked to impairments in cognition and emotional behaviors in human psychiatric diseases [31]. Also, Jalili et al. [32] observed a significant decrease in the number of dendritic spines in hippocampal neurons in PTZinduced kindled rats. The reduction in dendritic spine might be attributed to the hypoxia resulted from the seizures [33-35].

In this study, the observed astrogliosis in PTZ-treated group, as revealed from the increase in GFAP expression, was previously reported in the brains of patients with epilepsy and in animal models of this disorder [36]. Also, the astrocytic morphological changes observed ultrastructurally in PTZtreated group might be implicated in the pathophysiology of epilepsy. As astrocytes play a role in the supply of neurotransmitter precursors at excitatory and inhibitory synapses [37]. Astrocytic changes contribute to the circuit hyperexcitability that is the hallmark of epilepsy and gliosis was linked to disrupted uptake and metabolism of glutamate and neurotransmitter supply, particularly in inhibitory neurons [36]. Our data (Table 4, Fig. 9) showed the biggest distinction between the control and PTZ-treated groups at P10, not at P90. Although some data indicated that astrogliosis inhibits axonal regeneration [38], there is a concept that GFAP might play an important role in the control of neurological disease. It was observed that GFAP added structural stabilization of white matter in mice with experimental autoimmune encephalomyelitis [39], which might indicate that in young age the brain is more protected. Consistently, Huang et al. [29] suggested that the immature brain is less vulnerable to seizure-induced injury than is that in adult animals.

Acute treatment with PTZ-induced epileptic seizures caused toxic effect on the structure of rat DG at different postnatal ages. Most structural changes observed in this study in the rat DG were less in P10 and became more intense with the progress of age. The advanced astrogliosis detected in treated P10 might be a protective morphological change form seizure-induced injury in P10.

\section{ORCID}

Heba K. Mohamed:

https://orcid.org/0000-0003-4097-796X

Sohair A. Eltony: https://orcid.org/0000-0003-2710-0565

\section{Author Contributions}

Conceptualization: HKM. Data acquisition: HKM, SAE.
Data analysis or interpretation: SAE. Drafting of the manuscript: SAE. Critical revision of the manuscript: SAE. Approval of the final version of the manuscript: all authors.

\section{Conflicts of Interest}

No potential conflict of interest relevant to this article was reported.

\section{Acknowledgements}

Assiut University is the source of funding for this research.

\section{References}

1. Rajabzadeh A, Bideskan AE, Fazel A, Sankian M, Rafatpanah $\mathrm{H}$, Haghir H. The effect of PTZ-induced epileptic seizures on hippocampal expression of PSA-NCAM in offspring born to kindled rats. J Biomed Sci 2012;19:56.

2. Chawla S, Aneja S, Kashyap R, Mallika V. Etiology and clinical predictors of intractable epilepsy. Pediatr Neurol 2002;27:186-91.

3. Siddiqui AH, Joseph SA. CA3 axonal sprouting in kainateinduced chronic epilepsy. Brain Res 2005;1066:129-46.

4. Buckmaster PS, Abrams E, Wen X. Seizure frequency correlates with loss of dentate gyrus GABAergic neurons in a mouse model of temporal lobe epilepsy. J Comp Neurol 2017;525:2592-610.

5. LaJoie J, Moshé SL. Effects of seizures and their treatment on fetal brain. Epilepsia 2004;45 Suppl 8:48-52.

6. Holter NI, Zuber N, Bruehl C, Draguhn A. Functional maturation of developing interneurons in the molecular layer of mouse dentate gyrus. Brain Res 2007;1186:56-64.

7. Sadgrove MP, Laskowski A, Gray WP. Examination of granule layer cell count, cell density, and single-pulse BrdU incorporation in rat organotypic hippocampal slice cultures with respect to culture medium, septotemporal position, and time in vitro. J Comp Neurol 2006;497:397-415.

8. Li Y, Mu Y, Gage FH. Development of neural circuits in the adult hippocampus. Curr Top Dev Biol 2009;87:149-74.

9. Porter BE. Neurogenesis and epilepsy in the developing brain. Epilepsia 2008;49 Suppl 5:50-4.

10. Morimoto K, Fahnestock M, Racine RJ. Kindling and status epilepticus models of epilepsy: rewiring the brain. Prog Neurobiol 2004;73:1-60.

11. Aniol VA, Ivanova-Dyatlova AY, Keren O, Guekht AB, Sarne Y, Gulyaeva NV. A single pentylenetetrazole-induced clonic-tonic seizure episode is accompanied by a slowly developing cognitive decline in rats. Epilepsy Behav 2013;26:196-202.

12. Hassan AF, Abedelhaffez AS. Influence of hypo-osmolality and induced seizures on blood brain barrier permeability and brain concentrations of trace elements in rats. Ibnosina J Med Biomed Sci 2013;5:62-72. 
13. Cole TB, Robbins CA, Wenzel HJ, Schwartzkroin PA, Palmiter RD. Seizures and neuronal damage in mice lacking vesicular zinc. Epilepsy Res 2000;39:153-69.

14. Drury RA, Wallington EA. Carelton's histological technique. 5th ed. Oxford: Oxford University Press; 1980.

15. Gupta PD. Ultrastructural study on semithin section. Sci Tools 1983;30:6-7.

16. Rodier PM. Chronology of neuron development: animal studies and their clinical implications. Dev Med Child Neurol 1980;22:525-45.

17. Romijn HJ, Hofman MA, Gramsbergen A. At what age is the developing cerebral cortex of the rat comparable to that of the fullterm newborn human baby? Early Hum Dev 1991;26:61-7.

18. Abdelrahim EA, Eltony SA. Postnatal development of the hippocampal formation in male albino rats: histological, immunohistochemical, and morphometric studies. Egypt J Histol 2011;34:346-64.

19. Gaarskjaer FB. The development of the dentate area and the hippocampal mossy fiber projection of the rat. J Comp Neurol 1985;241:154-70.

20. Kherani ZS, Auer RN. Pharmacologic analysis of the mechanism of dark neuron production in cerebral cortex. Acta Neuropathol 2008;116:447-52.

21. Karimzadeh F, Hosseini M, Mangeng D, Alavi H, Hassanzadeh GR, Bayat M, Jafarian M, Kazemi H, Gorji A. Anticonvulsant and neuroprotective effects of Pimpinella anisum in rat brain. BMC Complement Altern Med 2012;12:76.

22. Mansouri S, Ataei ML, Hosseini M, Bideskan AR. Tamoxifen mimics the effects of endogenous ovarian hormones on repeated seizures induced by pentylenetetrazole in rats. Exp Neurobiol 2013;22:116-23.

23. Homayoun M, Seghatoleslam M, Pourzaki M, Shafieian R, Hosseini M, Ebrahimzadeh Bideskan A. Anticonvulsant and neuroprotective effects of Rosa damascena hydro-alcoholic extract on rat hippocampus. Avicenna J Phytomed 2015;5:260-70.

24. Pourzaki M, Homayoun M, Sadeghi S, Seghatoleslam M, Hosseini M, Ebrahimzadeh Bideskan A. Preventive effect of Coriandrum sativum on neuronal damages in pentylentetrazoleinduced seizure in rats. Avicenna J Phytomed 2017;7:116-28.

25. Pavlova TV, Yakovlev AA, Stepanichev MY, Mendzheritskii AM, Gulyaeva NV. Pentylenetetrazole kindling induces activation of caspase-3 in the rat brain. Neurosci Behav Physiol 2004;34:45-7.

26. Shin EJ, Jeong JH, Chung YH, Kim WK, Ko KH, Bach JH, Hong JS, Yoneda Y, Kim HC. Role of oxidative stress in epileptic seizures. Neurochem Int 2011;59:122-37.
27. Kim YJ, Jung YW. Regulation of neurogenesis and apoptosis through the NHE1 in lithium-treated rat dentate gyrus. Korean J Anat 2009;42:257-63.

28. Jiang M, Lee CL, Smith KL, Swann JW. Spine loss and other persistent alterations of hippocampal pyramidal cell dendrites in a model of early-onset epilepsy. J Neurosci 1998;18:8356-68.

29. Huang LT, Yang SN, Liou CW, Hung PL, Lai MC, Wang CL, Wang TJ. Pentylenetetrazol-induced recurrent seizures in rat pups: time course on spatial learning and long-term effects. Epilepsia 2002;43:567-73.

30. Penzes P, Cahill ME, Jones KA, VanLeeuwen JE, Woolfrey KM. Dendritic spine pathology in neuropsychiatric disorders. Nat Neurosci 2011;14:285-93.

31. Lin YC, Koleske AJ. Mechanisms of synapse and dendrite maintenance and their disruption in psychiatric and neurodegenerative disorders. Annu Rev Neurosci 2010;33:349-78.

32. Jalili C, Salahshoor MR, Pourmotabbed A, Moradi S, Roshankhah Sh, Darehdori AS, Motaghi M. The effects of aqueous extract of Boswellia Serrata on hippocampal region CA1 and learning deficit in kindled rats. Res Pharm Sci 2014;9:351-8.

33. Segura I, Lange C, Knevels E, Moskalyuk A, Pulizzi R, Eelen G, Chaze T, Tudor C, Boulegue C, Holt M, Daelemans D, Matondo $\mathrm{M}$, Ghesquière $\mathrm{B}$, Giugliano $\mathrm{M}$, Ruiz de Almodovar C, Dewerchin M, Carmeliet P. The oxygen sensor PHD2 controls dendritic spines and synapses via modification of filamin A. Cell Rep 2016;14:2653-67.

34. Stoyanova II, Hofmeijer J, van Putten MJ, le Feber J. Acyl ghrelin improves synapse recovery in an in vitro model of postanoxic encephalopathy. Mol Neurobiol 2016;53:6136-43.

35. Le Feber J, Erkamp N, van Putten MJ, Hofmeijer J. Loss and recovery of functional connectivity in cultured cortical networks exposed to hypoxia. J Neurophysiol 2017;118:394-403.

36. Coulter DA, Steinhäuser C. Role of astrocytes in epilepsy. Cold Spring Harb Perspect Med 2015;5:a022434.

37. Halassa MM, Haydon PG. Integrated brain circuits: astrocytic networks modulate neuronal activity and behavior. Annu Rev Physiol 2010;72:335-55.

38. Zhang D, Hu X, Qian L, O'Callaghan JP, Hong JS. Astrogliosis in CNS pathologies: is there a role for microglia? Mol Neurobiol 2010;41:232-41.

39. Liedtke W, Edelmann W, Chiu FC, Kucherlapati R, Raine CS. Experimental autoimmune encephalomyelitis in mice lacking glial fibrillary acidic protein is characterized by a more severe clinical course and an infiltrative central nervous system lesion. Am J Pathol 1998;152:251-9. 